\title{
A hybrid decision support system for analyzing challenges of the agricultural supply chain
}

Bhaskar B.Gardas ${ }^{a}$ Rakesh D.Raut ${ }^{\mathrm{b}}$ Naoufel Cheikhrouhou ${ }^{\mathrm{B}}$ Balkrishna E. Narkhede ${ }^{\mathrm{d}}$

8, Saboo Siddik Polytechnic Road, New Nagpada, Byculla, Mumbai, Maharashtra 400008, India

Operations and Supply Chain Management, National Institute of Industrial Engineering (NITIE), Vihar Lake, Mumbai 400 087, Maharashtra, India

Geneva School of Business Administration, University of Applied Sciences Western

Switzerland (HES-SO), 1227 Carouge, Switzerland

Department of Industrial Engineering, National Institute of Industrial Engineering (NITIE), Vihar Lake, NITIE, Powai, Mumbai, Maharashtra, 400087, India 


\title{
An integrated Delphi-DEMATEL-ISM approach for analysing the challenges of agricultural supply chains
}

\begin{abstract}
Agricultural supply chain management (ASCM) covers all the activities involved in moving products of agri-sector from the field to the customer, and it helps to enhance the production, cultivation and improving economic growth of the nation. The purpose of the paper is to identify the challenges of ASCM in India through an integrated method using Delphi, decisionmaking trial and evaluation laboratory (DEMATEL), and interpretive structural modelling (ISM). In the present investigation, eleven crucial ASCM challenges are identified through a literature survey and Delphi technique. DEMATEL identifies the cause-effect interrelationship diagram, and the systematic hierarchical structures of ASCM challenges are efficiently discussed through ISM. The implementation of the approach in an Indian context shows that two factors, namely limited integration among the national agricultural markets, and limited agricultural market infrastructure are the most important ones. The integrated model intends to guide the agricultural policy makers and decision makers at various stages of the supply chain for improving the performance of ASCM in India.
\end{abstract}

Keywords: Agricultural supply chain management; multi-criteria decision making; DEMATEL; ISM; MICMAC analysis; India.

\section{Introduction}

Agricultural supply chain management (ASCM) intends to move agricultural products from the farmers to the end users. Various interconnected activities are involved in this process such as production planning, producing, harvesting, grading, packing, transporting, storing, processing, distributing, publicity, and sales (Vyas, 2014). It plays an important role in boosting the production and consumption and accelerates the financial growth (Najafabadi, 2011). In recent times, ASCM had become very challenging due to the complexity linked to the involvement of latest technologies, communication, transportation, economic transactions among the countries, intermediaries, and traders.

The primary objectives of the ASCM are to help farmers get fair returns, to reduce the difference in prices between farmers and customers, and to ensure acceptable product quality (Madhavedi, 2010). India has a substantial agricultural base, which is attracting multinational companies in the fast food and processed food domains, creating challenges as well as 
opportunities in the ASCM domain. It should be noted that farmers' land holdings are becoming smaller and they are not able to invest and gain benefits from the crops. On the other side, prices of the agricultural products are falling, whereas the input costs are increasing (Vyas, 2014). In ASCM, there is a significant risk of perishability depending on the type of agricultural products, and seasonality of the production, which includes uncertainty of the rainfall and climatic conditions. Indeed, the cost of an agricultural commodity depends on the perishability, seasonality, and demand and supply equations (Rao, 2008; Vyas, 2014).

This paper explores the crucial challenges of ASCM in the Indian context and develops a causeeffect diagram and hierarchical structural model to identify the essential agricultural SCM hindrances. The remainder of this article is arranged as follows. Section 2 focuses on the survey of literature and section 3 details research methodology. Section 4 highlights the DEMATEL and ISM model development. Whereas, section 5 covers the results \& discussion of the investigation, and conclusion of the research is detailed in section 6. Lastly, section 7 covers limitations, future scope, and managerial implications.

\section{Literature review}

India has increased the agricultural production to meet the continuous increase in the demand, however it lacks considerably in the area of agricultural SCM. This incapability is becoming more severe with significant changes taking place in the ASCM in the national and international markets. This area has attracted many researchers all over the globe, and some of the published articles in the case sector are briefed in this section. This segment highlights the research articles published in the domain of ASCM within the multi-criteria environment, applications of DEMATEL, ISM, and integrated DEMATEL-ISM approach.

\subsection{Papers published in the area of Agricultural and food-SCM (ASCM)}

Allaoui et al., (2018) analyse the sustainable agro-food supply chain design using a two-stage hybrid multi-objective analytical hierarchy process decision-making approach. Mele et al., (2009) discuss a sugarcane supply chain case with the purpose of minimisation of total supply chain cost and environmental impact. For this reason, the authors developed a decision support system based on a mixed integer linear programming model. Naik and Suresh (2018) analyse the barriers of creating sustainable agri-retail supply chains. The primary focus of the study was how to engage small farmers in a sustainable agri-retail supply chain business. Banaeian et al. (2018) present a case study from the agri-supply chain industry with the purpose of green 
supplier selection within a fuzzy environment by using an integrated multi-criteria decisionmaking tool (i.e. The Technique for Order of Preference by Similarity to Ideal Solution (TOPSIS)- VlseKriterijumska Optimizacija I Kompromisno Resenje -Gray Relation Analysis (GRA). It was concluded that fuzzy GRA required less computational difficulty for generating similar results. Validi et al. (2014) propose a decision support system by employing a multiobjective tool for the sustainable food supply chain distribution system. Ahumada \& Villalobos (2009) review the literature related to MCDM approaches applied to measure performance in food supply chains, and recommend that there is a need to do more research in food supply chains. Numerous researchers discuss the agri-food sector challenges, and sustainable agrifood supply chain management issues that significantly affect the latest theoretical contribution in food science and industry (Green, 2010; Gupta and Palsule-Desai, 2011). Roy et al. (2009), Savino et al. (2014), Garnett (2014), Pawelzik et al. (2013), Herath et al. (2013), Virtanen et al. (2011), Wognum et al. (2011) highlight the challenges and opportunities in environmental assessment and life cycle assessment of agri-food supply chain. Banasik et al. (2017) present a mushroom case study of agricultural supply chains using multi-objective optimisation linear programming tool to evaluate trade-offs between economic and environmental factors. Ahumada and Villalobos (2011) investigate the operational model for planning the harvest and distribution of perishable agricultural products and focus on the productivity of manufacturers/farmers which are heavily dependent on the handling of small period planning in the harvest time. The study recommends that essential funds can be obtained by managing the trade-off between the cleanliness of the transport of the product with the added labour and transportation cost on the farmer's side. Tsolakis et al. (2014) show the results of a detailed and critical study on agri-food supply chain management based on a hierarchy decision-making approach. The findings of the study demonstrate that agri-food supply chain management is a rapidly developing research area, focusing on addressing case-dependent issues related to different supply chain tiers. The principle finding of the study is to focus less on developing hybrid tool approaches for the optimisation of the complete supply chain. Shukla and Jharkharia (2013) present a critical and in-depth literature survey of fruits and vegetable (agrifood) supply chain management. The article focuses on two essential aspects: 1) consumer satisfaction, and 2) revenue maximisation with post-harvest waste reduction. Sagheer et al. (2009) develop a research framework for analysing the competitiveness of India's agri-food supply chain. The framework is based on two important factors: human and non-human factors, and the methodology used for this was value chain analysis and Porter's diamond model. 
Gokarn and Kuthambalayan (2017) identify the 33 challenges of waste reduction in Indian agrifood supply chain using interpretative structural modelling and exploratory factor analysis.

Bartolini et al. (2007) use multi-criteria linear programming models for studying the influence of water and agricultural strategy on irrigated farming systems in Italy. The results highlight the effects of irrigated systems diversity and the agricultural policy in the technological and market scenarios. It concludes that the water pricing policy would have less influence as compared to the agricultural policy. Piech and Rehman (1993) apply goal programming (GP), multi-objective programming (MOP), and complex programming (CP) for effective farm planning in the UK and compare the results obtained by these three methods. Prakash (2003) addresses the uncertainty in the analysis of land suitability for crops in Italy using AHP, TOPSIS, and fuzzy AHP. It was concluded that the fuzzy AHP provided the best results as compared to other two methodologies. Qiu (2005) assesses the environmental and economic impact of decisions on farming in an agricultural watershed using a weighted sum model approach.

Tiwari et al. (1999) develop a decision-making framework for the selection criteria which focus on the economic and environmental dimensions in lowland irrigated agricultural systems using GIS, CP, and AHP. Balaji and Arshinder (2016) develop a structural model of 16 causative factors of food waste by employing ISM, and total ISM approaches. After analysis, the results reveal that shortage of scientific harvesting methods and significant number of mediators were important factors and need the attention of the decision makers for reducing food waste.

\subsection{Applications DEMATEL and hybrid methodology}

The DEMATEL method has been accepted by most of the academic community and industry experts and is considered the most suitable method to deal with the cause-effect relationship and interdependence among the evaluation factors (Hsu et al., 2013; dos Muchangos et al., 2015). The DEMATEL method is used in many research articles such as implementation barriers of green supply chain management in Canadian firms (Kaur et al., 2018); rough DEMATEL based approach for evaluating interaction between requirements of productservice system, an approach applied in an air compressor system (Song and Cao, 2017); Li and Mathiyazhagan (2018) apply DEMATEL for identifying the significant factors for the adoption of sustainable supply chain in the automobile manufacturing field in north India; to analyse 
patent citation, Altuntas and Dereli (2015) apply DEMATEL; Bai and Sarkis (2013) use a greybased DEMATEL approach for evaluating critical success criteria of business process management; Büyüközkan and Güleryüz (2016) apply hybrid DEMATEL-ANP based technique in renewable energy sector in Turkey; Govindan and Chaudhuri (2016) use DEMATEL to analyse the interrelationships of risks faced by third-party logistics service providers; Ocampo et al., (2018) use fuzzy DEMATEL in the hospitality industry sector; Venkatesh et al., (2017) apply Delphifuzzy DEMATEL to prioritize barriers to coastal shipping development for effective policy interventions.

\subsection{ISM methodology applications}

The ISM approach is a multi-criteria decision making (MCDM) tool for establishing the mutual relationship between parameters or variables of an issue studied and is widely utilised in literature.

Pfohl et al. (2011) model 26 risk factors in a supply chain (SC), and it found that a risk factor, namely natural disasters was found to be the most important among all other criteria. Grzybowska (2012) explores 16 sustainability enablers in a SC and analyses their interrelationship. An enabler, namely commitment from top management, is found to be very important and drives all other enablers. Govindan et al. (2013) identify ten factors and study the interrelationship among the lean, resilient practices, and green SC performance. It concludes that six variables were most significant, namely wastage of business, eco-friendly friendly packaging, transportation flexibility, just in time (JIT), ISO 14001, and operational cost. Luthra et al. (2015) establish the interrelationship between the barriers for implementing the GSCM towards sustainability. The most significant factor identified is natural resources shortage. Ravi (2015) analyses the interrelationship between the hindrances to eco-efficiency in the electronic packaging sector. Three barriers namely lack of top management commitment, lack of awareness regarding the ecological problems, and short-term decision-making perspectives were the barriers having high driving power. Beikkhakhian et al. (2015) uses ISM methodology for evaluating and ranking the agile supplier criteria. Results reveal that factors, namely the speed of delivery, reduction of cost, and reduction of lead time were found to be the most significant. A fuzzy analytic hierarchy process (AHP) is used in weighing the criteria and fuzzy technique for order preference by similarity to ideal solution (TOPSIS) methodology for ranking the suppliers. Ren et al. (2015) use fuzzy analytic network process (ANP) and ISM approach to identify and rank the hindrances that influence the sustainability of shale gas 
revolution and it found that the barriers namely lack of governmental support, lack of core technologies, and lack of standards \& regulations, were the most significant barriers.

\subsection{Applications of integrated DEMATEL- ISM methodology}

Song et al. (2015) develop the structural model of social risk of rail transit construction. Safdari Ranjbar et al. (2014) determined the internal organizational criteria in a strategy implementation by using a hybrid DEMATEL-ISM approach. Ashtianipour and Zandhessami (2015) apply the DEMATEL- ISM based approach to evaluate the influence of technological innovation competences on SMEs. Dos Muchangos et al. (2015) apply ISM-DEMATEL method for analysing the restrictions to municipal solid waste management. Bag (2017) use the hybrid ISM-DEMATEL tool for analysing drivers of green procurement. Kumar and Dixit (2018) use ISM-DEMATEL approach of analysing the hindrances to e-waste management practices in India. Wang et al. (2018) apply hybrid DEMATEL and ISM approach for analysing the influencing factors of mining safety.

\subsection{Research Gaps}

The literature survey section shows that considerable studies have been carried out in the field of ASCM using MCDM approaches for addressing various supply chain issues. Nevertheless, very few works have been carried out in agricultural supply chains using MCDM methodologies. It is worth mentioning that, the present research paper is the first research framework concentrating on the ASCM challenges using integrated DEMATEL-ISM methodology. The hierarchical model in MCDM techniques depends extensively on the level of dominance of two variables considered for the analysis for which experts' judgments are required. In the ISM approach, the dominance level is not needed, only the mutual relationship among the variables needs to be established. Hence, in this investigation, DEMATEL-ISM approach is employed for modelling the crucial ASCM challenges.

\section{Research methodology}

The main objective of this investigation is to formulate a structural framework to integrate DEMATEL-ISM methodology to identify the cause-effect relationship, mutual interrelationship, and to explore the influential power and dependency magnitudes of the identified critical ASCM challenges in the Indian context. Both DEMATEL and ISM are adapted to the analysis and decision-making in critical and complex situations (De-Qun, \& 
Ling , 2008). The integration of DEMATEL and ISM strengthens the approach and supports the process of decision-making, as they supplement each other (dos Muchangos et al., 2015). DEMATEL aids in identifying the cause-effect interrelationship among the criteria. Whereas, the ISM tool helps in building the relationship between the criteria (Wang et al., 2018). The framework of the methodology is shown in Figure 1 and detailed in the subsequent section.

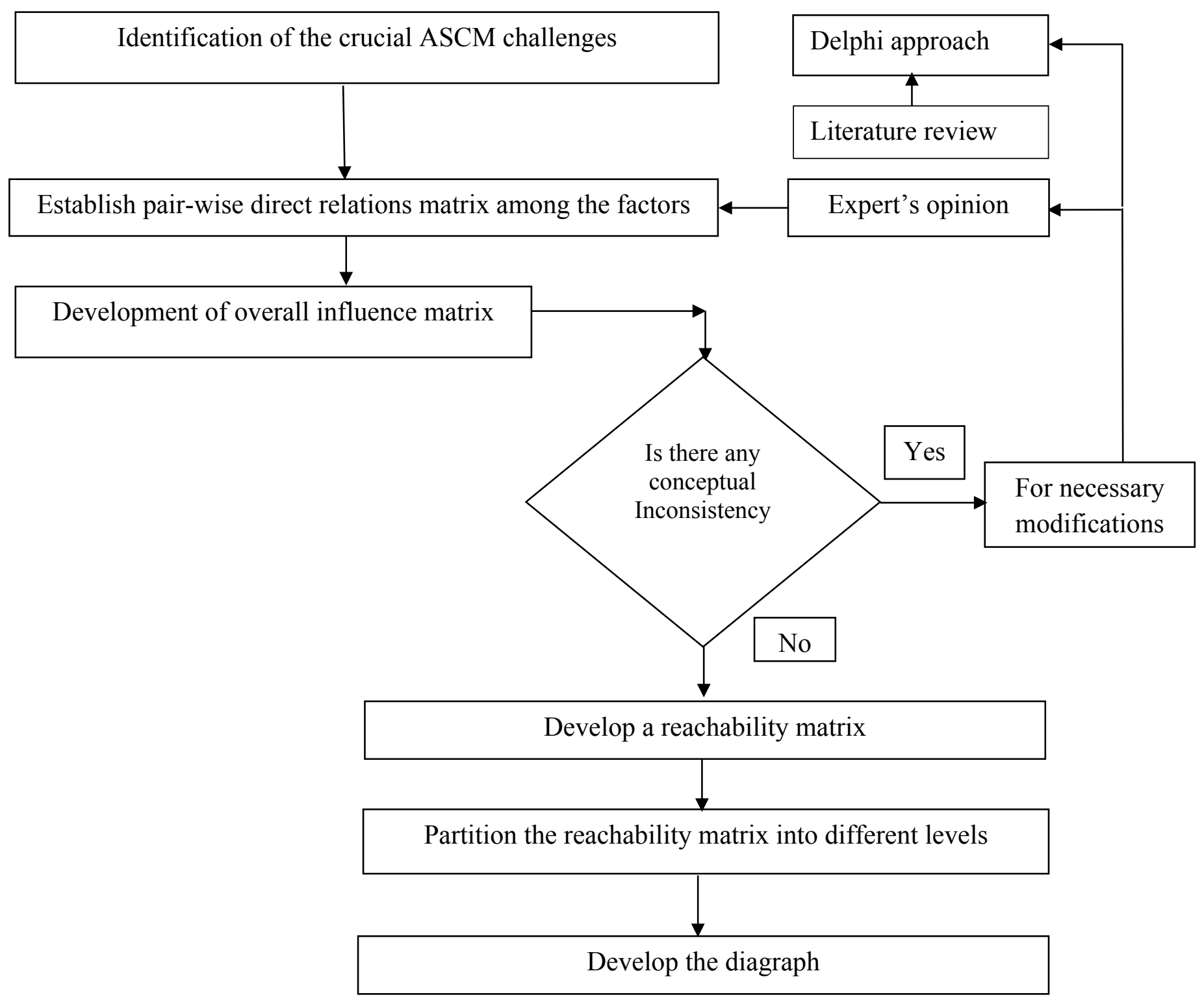

Figure 1 Methodology description of the Delphi- DEMATEL- ISM model of critical ASCM challenges 


\subsection{Integrated DEMATEL-ISM approach}

Decision Making and Trial Evaluation Laboratory (DEMATEL) methodology helps visualising the causal relationships structure between the criteria. DEMATEL analysis generates graphics output (or digraphs) of a causal relationship between the variables, and particularly the variables that are having a central role, i.e. greatest influence power (Awasthi and Grzybowska, 2014; Büyüközkan and Güleryüz, 2016).

We summarise the procedure of DEMATEL in four steps as:

- Step 1- Development of pair-wise direct relations matrix between the system variables by obtaining the relationships.

- Step 2- Normalizing the direct relations matrix to determine the initial influence matrix.

- Step 3- Finding the total relation matrix.

- Step 4- Determining relative strengths of the variables through the causal diagram.

The different steps followed for the calculations are shown below (Awasthi and Grzybowska, 2014; Kaur et al.2018):

Step 1: Determination of direct relationship matrix

Let $m=$ variables/criteria/challenges. Suppose $\mathrm{A}_{\mathrm{k}}$ is the $m * m$ matrix obtained by filling the matrix entries by 3 levels of influence with values given below:

0 - No influence (factor $a_{i}$ does not influence $a_{j}$ )

1 - moderate influence (factor $\mathrm{a}_{\mathrm{i}}$ has moderate influence over $\mathrm{a}_{\mathrm{j}}$ )

2 - high influence (if factor $\mathrm{a}_{\mathrm{i}}$ has high influence over $\mathrm{a}_{\mathrm{j}}$ )

Suffix $i, j$ is used for row and column respectively.

$$
A=\left[\begin{array}{ccccc}
a_{11} & \ldots & a_{1 j} & \ldots & a_{1 m} \\
\ldots & & \ldots & & \ldots \\
a_{i 1} & \ldots & a_{i j} & \ldots & a_{i m} \\
\ldots & & \ldots & & \ldots \\
a_{m 1} & \ldots & a_{m j} & \ldots & a_{m m}
\end{array}\right]
$$

Step 2: Normalized direct relationship matrix

The $m * m$ normalised direct relation matrix $\mathrm{N}$ is found from the matrix of step 1 by multiplying A by $\mathrm{S}$, where $\mathrm{S}$ is given by

$\mathrm{S}=\min \left\{1 / \operatorname{maxi} \sum_{j=1}^{m}\left|a_{i j}\right|, 1 / \operatorname{maxj} \sum_{i=1}^{m}\left|a_{i j}\right|\right\}$

Major diagonal elements are zero in this matrix. 
Step 3: Determine total influence matrix $(\mathrm{T})$

A continuous decrease of the indirect effects of problems along the powers of $\mathrm{N}$, e.g. $\mathrm{N}_{2}, \mathrm{~N}_{3} \ldots$ $\mathrm{N}_{\mathrm{h}}$ and $\lim _{m \rightarrow \infty} N^{h}=[0]_{m X m}$, where $\mathrm{N}=\left[n_{i j}\right]_{m X m}, 0 \leq n_{i j}<1,0 \leq \sum_{i} n_{i j}<1,0 \leq \sum_{j} n_{i j}<1 \&$ at least one column sum $\sum_{j} n_{i j}$ or one row sum $\sum_{i} n_{i j}=1$.

The total influence matrix is given by-

$\mathrm{T}=\mathrm{N}+\mathrm{N}_{2}+\ldots+\mathrm{N}_{\mathrm{h}}=\mathrm{N}(1-\mathrm{N})^{-1}, \quad$ when $\lim _{h \rightarrow \infty} N^{h}=[0]_{m X m}$

Where $\mathrm{T}=\left[t_{i j}\right]_{n X n}$, for $\mathrm{i}, \mathrm{j}=1,2 \ldots \mathrm{n}$ and $(\mathrm{I}-\mathrm{N})(\mathrm{I}-\mathrm{N})-1=\mathrm{I}$.

$\mathrm{R}=(\mathrm{R} 1, \ldots, \mathrm{Ri}, \ldots . \mathrm{Rm})^{\prime}=(\mathrm{Ri}) \mathrm{mx} 1=\left[\sum_{j=1}^{m} t_{i j}\right] \mathrm{mx} 1$,

$\mathrm{C}=(\mathrm{C} 1, \ldots, \mathrm{Cj}, \ldots \mathrm{Cm})^{\prime}=(\mathrm{Cj}) \mathrm{mx} 1=(\mathrm{Cj})^{\prime} 1 \mathrm{xm}=\left[\sum_{i=1}^{m} t_{i j}\right] 1 \mathrm{xm}$,

Where,

$\mathrm{Ri}$ - Row sum of the $\mathrm{i}^{\text {th }}$ row of matrix $\mathrm{T}$

$\mathrm{Cj}$ - Row sum of the $\mathrm{j}^{\text {th }}$ column of matrix $\mathrm{T}$

Ri represents the addition of the direct \& indirect effects of challenge $i$ on the other challenges. Whereas, 'Cj' expresses the sum of direct $\&$ indirect effects that challenge $j$ has obtained from the other challenge. Additionally, the sum of the row and column groups, ' $\mathrm{Ri}+\mathrm{Cj}$ ' provide an index of the power of influences given and received, that is, $\mathrm{Ri}+\mathrm{Cj}$ expresses the degree of the central role that factor ' $i$ ' plays in the numerical. If $\mathrm{Ri}-\mathrm{Cj}$ is positive, then factor ' $\mathrm{i}$ ' affects other factors, and if $\mathrm{Ri}$ - $\mathrm{Cj}$ is negative, then other factors influence factor ' $\mathrm{i}$ ' (Tzeng et al., 2007; Gardas et al., 2018a).

\subsubsection{Development of overall influence matrix}

Complete influence matrix reproduces the overall interrelationships between different criteria without considering the influence of individual criteria on itself, that can be denoted as a unit matrix ' $\mathrm{I}$ ', the overall influence matrix, represented by $\mathrm{T} 1\left(\mathrm{~T} 1=\left[t_{i j}\right]_{n X n}\right)$, can be expressed as

$\mathrm{T} 1=\mathrm{T}+\mathrm{I}$

\subsubsection{Development of reachability matrix}

The significant trait of the development of reachability matrix is to find ' $\lambda$ ' (threshold value). If the degree of influence of a criterion to other criterion surpasses $\lambda$, a response would be received by a stimulus, i.e., the factor/criterion/challenge can directly influence other criterion; 
if the influencing degree of a criterion to other criterion lesser than ' $\lambda$ ', the stimulus receives no response, i.e., the criterion shows no influence on other criterion (Gardas et al., 2018b; Leveson, 2011; Wang et al., 2018).

$G=\left\{\begin{array}{c}1, G i j \geq \lambda, i=1 \ldots ., n \\ 0, G i j<\lambda, i=1, \ldots ., n\end{array}\right.$

Step 5: the reachability matrix is partitioned into various levels.

Step 6: by considering the interrelationships from the reachability matrix the directed graph is drawn. Later, the links of transitivity are removed.

Step 7: the digraph is transformed into an ISM model of crucial challenges by replacing the nodal numbers with statements.

Step 8: the ISM model is checked and reviewed for any inconsistencies (Gardas et al., 2018c; Raut et al., 2018a).

\section{DEMATEL-ISM model development}

The proposed research methodology framework is showed in Figure 1. To identify the challenges in ASCM, experts from the academics \& industry were contacted. The Delphi approach helped to identify the 11 important challenges in the Indian context. In this investigation 22 experts were contacted for their inputs. The experts team in the case described consists of 3 research scholars working in the agriculture field, 3 agricultural consultants, 2 NGO's, 3 professors from the supply chain management department, 3 supply chain managers, 3 procurement managers, 2 intermediaries, and 3 farmers. Each expert has an experience in the range of 15-30 years, except two research scholars. The shortlisted 11 challenges are discussed below.

\subsection{Identification of the crucial criteria/challenges to ASCM}

The eleven challenges obtained through literature survey and Delphi technique are detailed below-

1. Limited integration among the national agricultural markets

In the existing system, the surplus of agricultural production of one region is moved to consumers through a network of agents or traders, and intermediaries, multiple marketplaces, and institutional firms. It may be noted that there is no proper directive of the physical market at the national level. Hence, there is an earnest need for developing a country level single 
agricultural produce market by eliminating all the current storage, movement, and licensing barriers (AMPR, 2013; Mishra and Bhandari, 2013; Eskola, 2005; Sorathia et al., 2005).

2. Delays in the development of infrastructure projects

ASCM infrastructure projects have an extended development period. The seasonal and accumulation of the small superfluity of agri-products are very expensive and a tedious process, which affects the financial viability of the infrastructure projects and discourages investments. Provisions should make for viability gap funds or subsidies or concessional funds, and finance should be made available quickly for attracting investments for infrastructure projects (AMPR, 2013).

\section{Limited agricultural market infrastructure}

The farmers need storage facilities for selling their products at the appropriate time. Due to inadequate facilities, products perish in the open air and at railway stations. It is found that open auction and covered platforms are available in $65 \%$ (approx.) of the markets, whereas 25 $\%$ markets were found to have average drying yards. There is a massive need for cold storage and grading facilities in the markets. It is very alarming that the estimated shortage of cold storage facilities is around $90 \%$ and the deficiency in grading facilities is more than $65 \%$. The rural regions not conclusively linked to the markets by roads. Due to transportation issues, many agricultural produce are wasted (Eskola, 2005; Lorentz et al., 2007; Mishra and Bhandari, 2013; Sharma and Singh, 2011; Singh et al., 2009; Sorathia et al., 2005; Sudarshan et al., 2013). Also, there is limited availability of electronic weighbridges in the markets. In various regions weight measures are not uniform, resulting in farmers experiencing an economic loss while selling the product. Lack of proper marketing channels forces the farmers to distress sale, which results in reduced income to the farmers and benefiting the middlemen (AMPR, 2013; Eskola, 2005; Roy, 2012; Vyas, 2014). An efficient market information system (MIS) needs to be implemented which is a vital tool in the process decision making and problem resolving. MIS involves the collection, storage, and utilising information for making better decisions on marketing and for improving its exchange (Rajendran and Kartikesan, 2014). There is a need of proper handling, packaging, and processing facilities (Kasso and Bekele, 2016; Kiaya, 2014; Negi and Anand, 2015).

\section{Lack of quality of produce}


Good quality seeds, favourable climatic conditions, and fine soil quality are important in boosting the production of agri sector. Many farmers in India are not aware of the fact that the good quality crop can effectively fight diseases and pests. The non-usage of quality seeds and improved fertilisers results in inferior quality products, and their prices are low in the markets (AMPR, 2013; Gardas et al., 2017a).

5. Heavy wastage losses in a supply chain

The post-harvesting losses (PHL) in India are significant and cause substantial economic losses. India is ahead of China in food waste and its negative impact on the natural resources (Gardas et al., 2017a). The Indian ministry of food processing estimated that agricultural produce of worth Rs 580 billion is getting wasted every year, which is a huge figure (Commodity Online, 2007). In the literature, the range of PHL is from $10 \%$ to $70 \%$, which is very significant and needs much attention (Gardas et al., 2018a; FAO, 2010; Kader, 2005; Kasso and Bekele, 2016; Prusky, 2011; Parfitt et al., 2010; AMPR, 2013).

\section{Less price realisation of agricultural produce by farmers}

The farmers receive a very small share of the consumer price, especially in perishable agricultural products, due to lack of infrastructure, poor holding capacity, and a greater number of mediators. Provisions should be made for adequate alternative marketing channels such as contract farming, direct marketing, etc. for reducing or eliminating the intermediaries, and for the farmer's economic gains (AMPR, 2013; Roy, 2012).

\section{Restricted access to markets of agri produce}

There is a significant dissimilarity in the density of regulated markets in various states across India, varying from $11,214 \mathrm{~km}^{2}$ in Meghalaya to $118 \mathrm{~km}^{2}$ in Punjab. Adequately regulated markets should be made available to farmers within a $5 \mathrm{~km}$ radius (AMPR, 2013).

\section{Licensing hurdles}

The mandatory need of owning a warehouse or shop for licensing of commission traders or agents in the agricultural produce market committee (APMC) markets has increased dominance and monopoly of these agents preventing the entry of entrepreneurs and competition in the regulated markets. Due to the unavailability of sufficient space for constructing warehouses, 
shops, etc., the agents dissuaded from the issuance of new licenses. The licensing system is useful, and there is a need for a simple and transparent system of registration (AMPR, 2013).

\section{High costs of marketing}

The efficiency of agricultural product marketing depends heavily on the marketing costs, as it affects the actual appointment of the prices, primarily by the marginal and small farmers because of their less marketable surplus, the substantial costs of transactions and less bargaining potential compared to organised agents or traders (AMPR, 2013).

\section{Increased market charges}

Markets of APMC are authorised to collect market fees in the range of 0.50 to $2.0 \%$ of the sales value of the agricultural produce. Also, charges of commission ranges between 1.0 to $2.50 \%$ in food grains, and 4.0 to $8.0 \%$ in vegetables \& fruits (V\&F). Also, other charges like unloading and loading charges (Hamal charges), purchase tax, and charges of weighment are also applicable. In some of the Indian states, total market charges go up to $15 \%$ (approximately) which is a considerable value (AMPR, 2013; Vyas, 2014).

\section{Long agricultural supply chains and a large number of marketing channels}

Conventional ASCM, supply chains in India are very long and have a greater number of mediators between the farmers and the end-users, which adds cost to the products without any value addition (AMPR, 2013).

4.2 Development of pair-wise direct relations matrix between the system variables using equation one shown in Table 1 to obtain the relationships.

4.3 Normalizing the direct relations matrix to determine initial influence matrix by using equation two shown in Table 2.

4.4 Determine total influence matrix by using equation three shown in Table 3.

4.5 Determining relative strengths of the variables through the causal diagram by using equation four shown in Table 4.

4.6 Development of overall influence matrix by using equation six shown in Table 5 and developing the cause-effect diagram based on R-C and R $+\mathrm{C}$, shown in Figure 2. 
4.7 Development of reachability matrix by using equation seven shown in Table 6. The threshold is $\lambda=0.148$, is calculated by taking the average of all the entries of total relation matrix. The inner dependency matrix (Table 6) is formulated by excluding items whose values are lesser than $\lambda$ in the total relation matrix. 


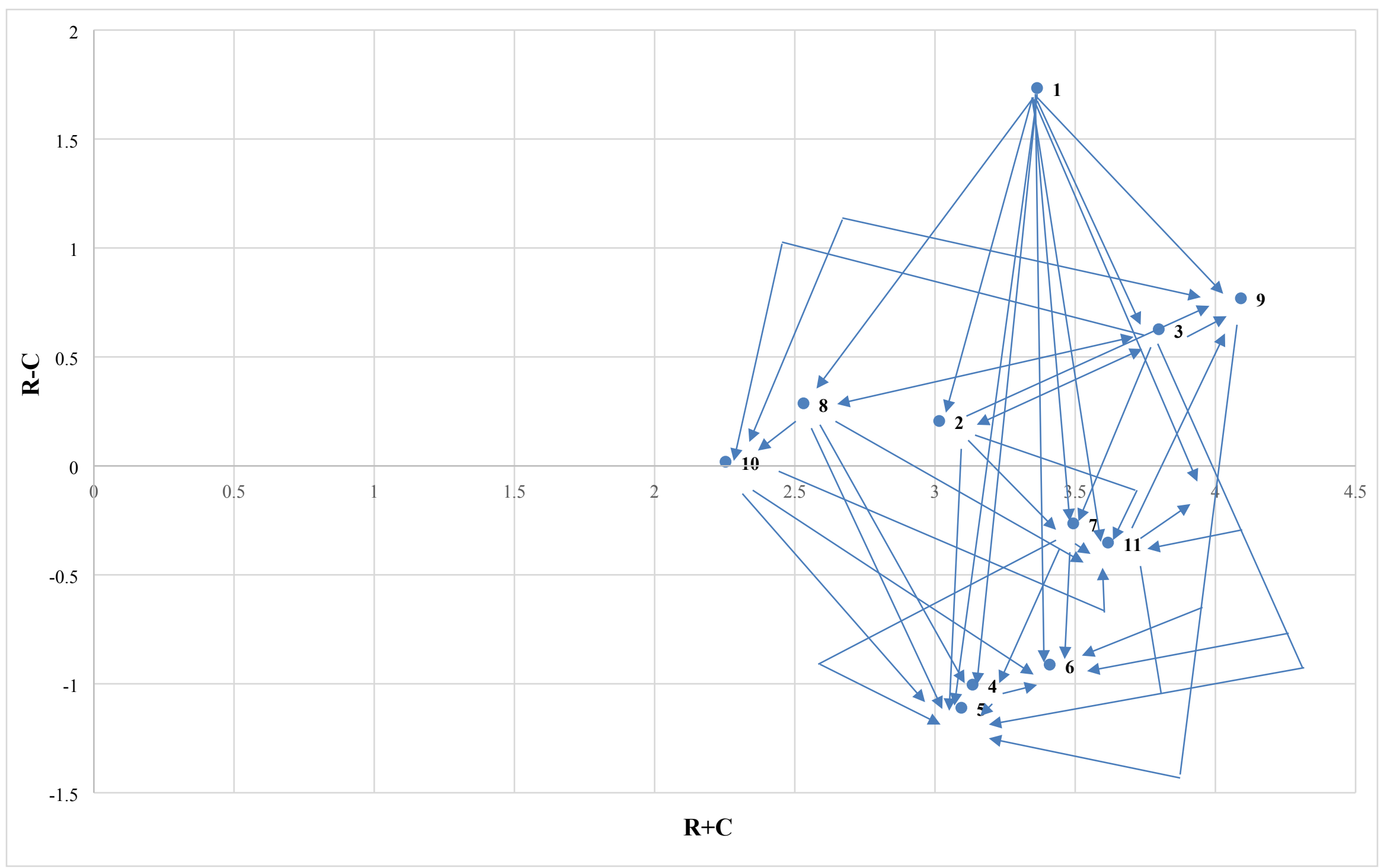


Figure 2 Cause-effect relationship diagram 
Table 1 Direct relation average matrix

\begin{tabular}{|c|c|c|c|c|c|c|c|c|c|c|c|}
\hline & $\mathbf{X 1}$ & $\mathbf{X 2}$ & $\mathbf{X 3}$ & $\mathbf{X 4}$ & $\mathbf{X 5}$ & $\mathbf{X 6}$ & $\mathbf{X 7}$ & $\mathbf{X 8}$ & $\mathbf{X 9}$ & $\mathbf{X 1 0}$ & $\mathbf{X 1 1}$ \\
\hline $\mathbf{X 1}$ & 0 & 2 & 1 & 2 & 0 & 1 & 1 & 1 & 1 & 1 & 1 \\
\hline $\mathbf{X 2}$ & 0 & 0 & 2 & 0 & 0 & 0 & 2 & 0 & 1 & 0 & 1 \\
\hline $\mathbf{X 3}$ & 0 & 0 & 0 & 0 & 2 & 2 & 1 & 1 & 1 & 1 & 2 \\
\hline $\mathbf{X 4}$ & 0 & 1 & 0 & 0 & 1 & 2 & 1 & 0 & 0 & 0 & 0 \\
\hline $\mathbf{X 5}$ & 1 & 1 & 0 & 0 & 0 & 0 & 1 & 0 & 0 & 1 & 0 \\
\hline $\mathbf{X 6}$ & 0 & 0 & 1 & 1 & 0 & 0 & 1 & 1 & 1 & 0 & 0 \\
\hline $\mathbf{X 7}$ & 1 & 0 & 1 & 2 & 1 & 1 & 0 & 0 & 0 & 0 & 1 \\
\hline $\mathbf{X 8}$ & 0 & 0 & 0 & 2 & 2 & 0 & 1 & 0 & 0 & 1 & 1 \\
\hline $\mathbf{X 9}$ & 0 & 1 & 1 & 0 & 1 & 1 & 0 & 1 & 2 & 1 & 2 \\
\hline $\mathbf{X 1 0}$ & 0 & 0 & 1 & 0 & 1 & 1 & 0 & 1 & 0 & 0 & 1 \\
\hline $\mathbf{X 1 1}$ & 1 & 1 & 0 & 2 & 1 & 1 & 0 & 0 & 1 & 0 & 0 \\
\hline
\end{tabular}


Table 2 Normalized direct influence matrix.

\begin{tabular}{|c|c|c|c|c|c|c|c|c|c|c|c|}
\hline & X1 & $\mathrm{X} 2$ & X3 & $\mathrm{X} 4$ & X5 & X6 & $\mathbf{X 7}$ & X8 & X9 & X10 & X11 \\
\hline X1 & 0.00 & 0.18 & 0.09 & 0.18 & 0.00 & 0.09 & 0.09 & 0.09 & 0.09 & 0.09 & 0.09 \\
\hline $\mathrm{X} 2$ & 0.00 & 0.00 & 0.18 & 0.00 & 0.00 & 0.00 & 0.18 & 0.00 & 0.09 & 0.00 & 0.09 \\
\hline X3 & 0.00 & 0.00 & 0.00 & 0.00 & 0.18 & 0.18 & 0.09 & 0.09 & 0.09 & 0.09 & 0.18 \\
\hline X4 & 0.00 & 0.09 & 0.00 & 0.00 & 0.09 & 0.18 & 0.09 & 0.00 & 0.00 & 0.00 & 0.00 \\
\hline X5 & 0.09 & 0.09 & 0.00 & 0.00 & 0.00 & 0.00 & 0.09 & 0.00 & 0.00 & 0.09 & 0.00 \\
\hline X6 & 0.00 & 0.00 & 0.09 & 0.09 & 0.00 & 0.00 & 0.09 & 0.09 & 0.09 & 0.00 & 0.00 \\
\hline $\mathbf{X 7}$ & 0.09 & 0.00 & 0.09 & 0.18 & 0.09 & 0.09 & 0.00 & 0.00 & 0.00 & 0.00 & 0.09 \\
\hline X8 & 0.00 & 0.00 & 0.00 & 0.18 & 0.18 & 0.00 & 0.09 & 0.00 & 0.00 & 0.09 & 0.09 \\
\hline X9 & 0.00 & 0.09 & 0.09 & 0.00 & 0.09 & 0.09 & 0.00 & 0.09 & 0.18 & 0.09 & 0.18 \\
\hline X10 & 0.00 & 0.00 & 0.09 & 0.00 & 0.09 & 0.09 & 0.00 & 0.09 & 0.00 & 0.00 & 0.09 \\
\hline X11 & 0.09 & 0.09 & 0.00 & 0.18 & 0.09 & 0.09 & 0.00 & 0.00 & 0.09 & 0.00 & 0.00 \\
\hline
\end{tabular}

Table 3 Total influence matrix

\begin{tabular}{|c|c|c|c|c|c|c|c|c|c|c|c|c|c|c|}
\hline & X1 & X2 & X3 & X4 & X5 & X6 & X7 & X8 & X9 & X10 & X11 & $\mathbf{R}$ & R-C & $\mathbf{R}+\mathbf{C}$ \\
\hline X1 & 0.066 & 0.289 & 0.237 & 0.349 & 0.194 & 0.289 & 0.263 & 0.182 & 0.239 & 0.174 & 0.266 & 2.549 & 1.734 & 3.364 \\
\hline $\mathbf{X 3}$ & 0.078 & 0.158 & 0.111 & 0.171 & 0.332 & 0.323 & 0.219 & 0.173 & 0.214 & 0.174 & 0.309 & 2.212 & 0.627 & 3.798 \\
\hline X5 & 0.118 & 0.137 & 0.073 & 0.078 & 0.065 & 0.075 & 0.157 & 0.040 & 0.053 & 0.123 & 0.075 & 0.992 & -1.110 & 3.094 \\
\hline X6 & 0.034 & 0.056 & 0.148 & 0.109 & 0.111 & 0.106 & 0.166 & 0.137 & 0.160 & 0.054 & 0.097 & 1.248 & -0.912 & 3.409 \\
\hline $\mathrm{X} 7$ & 0.136 & 0.094 & 0.165 & 0.292 & 0.199 & 0.226 & 0.115 & 0.061 & 0.089 & 0.059 & 0.179 & 1.615 & -0.264 & 3.493 \\
\hline $\mathbf{X 1 0}$ & 0.038 & 0.051 & 0.136 & 0.089 & 0.179 & 0.167 & 0.077 & 0.132 & 0.161 & 0.050 & 0.158 & 1.136 & 0.019 & 2.253 \\
\hline X11 & 0.129 & 0.135 & 0.099 & 0.277 & 0.189 & 0.214 & 0.122 & 0.063 & 0.192 & 0.061 & 0.104 & 1.633 & -0.352 & 3.617 \\
\hline $\mathrm{C}$ & 0.815 & 1.404 & 1.585 & 2.069 & 2.102 & 2.160 & 1.878 & 1.122 & 1.661 & 1.117 & 1.984 & 17.899 & & \\
\hline & & & & & & & & & & & $\lambda$ & 0.148 & & \\
\hline
\end{tabular}


Table 4 Relative Weights

\begin{tabular}{|c|c|c|c|}
\hline Rank & Cause-Effect group criteria & R-C & \\
\hline 1 & $\mathrm{X} 1$ & 1.73 & Cause \\
\hline 2 & $\mathrm{X} 9$ & 0.77 & Cause \\
\hline 3 & $\mathrm{X} 3$ & 0.63 & Cause \\
\hline 4 & $\mathrm{X} 8$ & 0.29 & Cause \\
\hline 5 & $\mathrm{X} 2$ & 0.21 & Cause \\
\hline 6 & $\mathrm{X} 10$ & 0.02 & Cause \\
\hline 1 & $\mathrm{X} 7$ & -0.26 & Effect \\
\hline 2 & $\mathrm{X} 11$ & -0.35 & Effect \\
\hline 3 & $\mathrm{X} 6$ & -0.91 & Effect \\
\hline 4 & $\mathrm{X} 4$ & -1.00 & Effect \\
\hline 5 & $\mathrm{X} 5$ & -1.11 & Effect \\
\hline
\end{tabular}

Table 5 Development of overall influence matrix of ASCM challenges

\begin{tabular}{|c|c|c|c|c|c|c|c|c|c|c|c|}
\hline & $\mathbf{X 1}$ & $\mathbf{X 2}$ & $\mathbf{X 3}$ & $\mathbf{X 4}$ & $\mathbf{X 5}$ & $\mathbf{X 6}$ & $\mathbf{X 7}$ & $\mathbf{X 8}$ & $\mathbf{X 9}$ & $\mathbf{X 1 0}$ & $\mathbf{X 1 1}$ \\
\hline $\mathbf{X 1}$ & 1.066 & 0.289 & 0.237 & 0.349 & 0.194 & 0.289 & 0.263 & 0.182 & 0.239 & 0.174 & 0.266 \\
\hline $\mathbf{X 2}$ & 0.057 & 1.072 & 0.261 & 0.124 & 0.139 & 0.143 & 0.267 & 0.066 & 0.195 & 0.065 & 0.222 \\
\hline $\mathbf{X 3}$ & 0.078 & 0.158 & 1.111 & 0.171 & 0.332 & 0.323 & 0.219 & 0.173 & 0.214 & 0.174 & 0.309 \\
\hline $\mathbf{X 4}$ & 0.034 & 0.129 & 0.072 & 1.077 & 0.148 & 0.242 & 0.170 & 0.040 & 0.060 & 0.032 & 0.061 \\
\hline $\mathbf{X 5}$ & 0.118 & 0.137 & 0.073 & 0.078 & 1.065 & 0.075 & 0.157 & 0.040 & 0.053 & 0.123 & 0.075 \\
\hline $\mathbf{X 6}$ & 0.034 & 0.056 & 0.148 & 0.109 & 0.111 & 1.106 & 0.166 & 0.137 & 0.160 & 0.054 & 0.097 \\
\hline $\mathbf{X 7}$ & 0.136 & 0.094 & 0.165 & 0.292 & 0.199 & 0.226 & 1.115 & 0.061 & 0.089 & 0.059 & 0.179 \\
\hline $\mathbf{X 8}$ & 0.055 & 0.078 & 0.163 & 0.270 & 0.272 & 0.113 & 0.179 & 1.038 & 0.052 & 0.134 & 0.156 \\
\hline $\mathbf{X 9}$ & 0.071 & 0.108 & 0.121 & 0.128 & 0.275 & 0.262 & 0.145 & 0.109 & 1.347 & 0.191 & 0.358 \\
\hline $\mathbf{X 1 0}$ & 0.038 & 0.051 & 0.136 & 0.089 & 0.179 & 0.167 & 0.077 & 0.132 & 0.161 & 1.050 & 0.158 \\
\hline $\mathbf{X 1 1}$ & 0.129 & 0.135 & 0.099 & 0.277 & 0.189 & 0.214 & 0.122 & 0.063 & 0.192 & 0.061 & 1.104 \\
\hline
\end{tabular}


Table 6 Development of reachability matrix of ASCM challenges

\begin{tabular}{|c|c|c|c|c|c|c|c|c|c|c|c|c|c|}
\hline Sr. No. & ASCM & $\mathbf{X 1}$ & $\mathbf{X 2}$ & $\mathbf{X 3}$ & $\mathbf{X 4}$ & $\mathbf{X 5}$ & $\mathbf{X 6}$ & $\mathbf{X} 7$ & $\mathbf{X 8}$ & $\mathbf{X 9}$ & $\mathbf{X 1 0}$ & $\mathbf{X 1 1}$ & Driving Power \\
\hline 1 & $\mathrm{X} 1$ & 1 & 1 & 1 & 1 & 1 & 1 & 1 & 1 & 1 & 1 & 1 & 11 \\
\hline 2 & $\mathrm{X} 2$ & 0 & 1 & 1 & 0 & 1 & 0 & 1 & 0 & 1 & 0 & 1 & 6 \\
\hline 3 & $\mathrm{X} 3$ & 0 & 1 & 1 & 0 & 1 & 1 & 1 & 1 & 1 & 1 & 1 & 9 \\
\hline 4 & $\mathrm{X} 4$ & 0 & 0 & 0 & 1 & 1 & 1 & 0 & 0 & 0 & 0 & 0 & 3 \\
\hline 5 & $\mathrm{X} 5$ & 0 & 0 & 0 & 0 & 1 & 0 & 0 & 0 & 0 & 0 & 0 & 1 \\
\hline 6 & $\mathrm{X} 6$ & 0 & 0 & 0 & 0 & 0 & 1 & 0 & 0 & 0 & 0 & 0 & 1 \\
\hline 7 & $\mathrm{X} 7$ & 0 & 0 & 0 & 1 & 1 & 1 & 1 & 0 & 0 & 0 & 1 & 5 \\
\hline 8 & $\mathrm{X} 9$ & 0 & 0 & 1 & 1 & 1 & 0 & 0 & 1 & 0 & 1 & 1 & 6 \\
\hline 9 & $\mathrm{X} 10$ & 0 & 0 & 0 & 0 & 1 & 1 & 0 & 0 & 1 & 1 & 1 & 5 \\
\hline 10 & $\mathrm{X} 11$ & 0 & 0 & 0 & 1 & 1 & 1 & 0 & 0 & 1 & 0 & 1 & \\
\hline 11 & & 1 & 3 & 4 & 5 & 10 & 8 & 4 & 3 & 6 & 5 & 8 & 5 \\
\hline
\end{tabular}


Table 7 Level partitions of the reachability matrix Iteration I to Iteration VI

\begin{tabular}{|c|c|c|c|c|}
\hline Sr. No. & Reachability Set & Antecedent Set & Intersection & Level \\
\hline 1 & $1,2,3,4,5,6,7,8,9,10,11$ & 1 & 1 & VI \\
\hline 2 & $2,3,5,7,9,11$ & $1,2,3$ & 2,3 & $\mathbf{V}$ \\
\hline 3 & $2,3,5,6,7,8,9,10,11$ & $1,2,3,8$ & $2,3,8$ & $\mathbf{V}$ \\
\hline 4 & $4,5,6$ & $1,4,7,8,11$ & 4 & II \\
\hline 5 & 5 & $1,2,3,4,5,7,8,9,10,11$ & 5 & $\mathbf{I}$ \\
\hline 6 & 6 & $1,3,4,6,7,9,10,11$ & 6 & I \\
\hline 7 & $4,5,6,7,11$ & $1,2,3,7$ & 7 & IV \\
\hline 8 & $3,4,5,8,10,11$ & $1,3,8$ & 3,8 & $\mathbf{V}$ \\
\hline 9 & $5,6,9,10,11$ & $1,2,3,9,10,11$ & $9,10,11$ & IV \\
\hline 10 & $5,6,9,10,11$ & $1,3,8,9,10$ & 9,10 & IV \\
\hline 11 & $4,5,6,9,11$ & $1,2,3,7,8,9,10,11$ & 9,11 & III \\
\hline
\end{tabular}




\subsection{Partitioning of levels}

From the final reachability matrix (FRM), for each factor/challenge, the antecedent, and the reachability sets were recognised. A factor having identical set values was eliminated and given the top hierarchical position in the structural model (Narkhede and Gardas, 2018; Raut et al., $2018 b)$. On the similar lines, all the factors were iterated to obtain different elimination levels. The partitioning of levels (6 levels) of all the causal factors is tabulated in Table 7.

\subsection{Structural model development}

A digraph was developed from the FRM and by eliminating the links of transitivity the final digraph was formed (Figure 3) (Jha et al., 2018). Later, the ISM model was structured by swapping the nodal numbers with the factor/challenge statements as shown in Figure 4. 


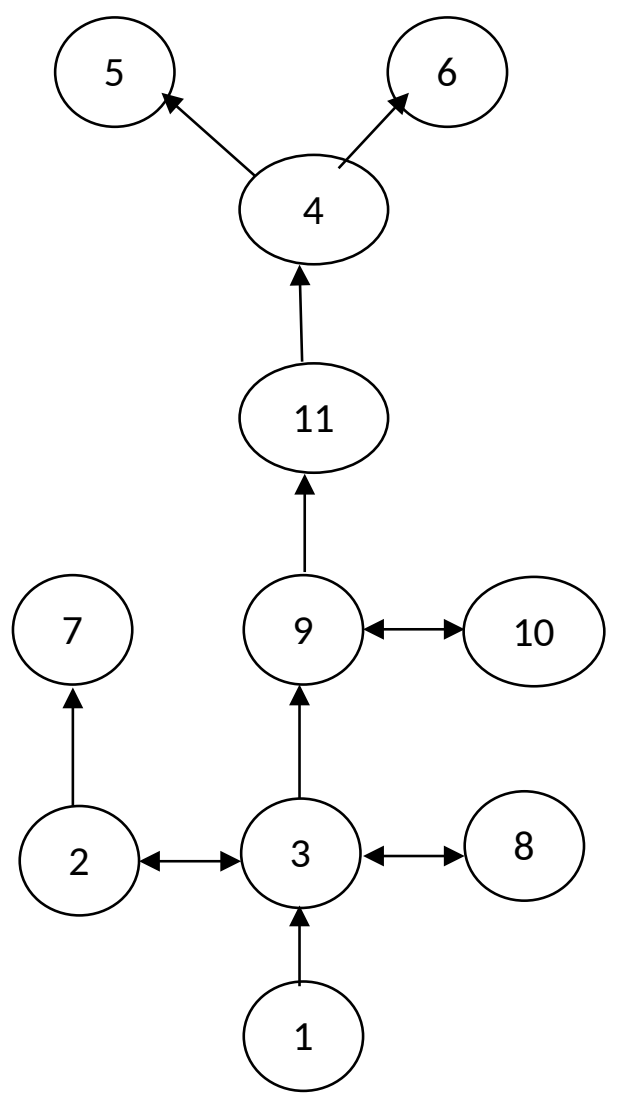

Figure 3 Final digraph depicting relationship among the critical challenges. 


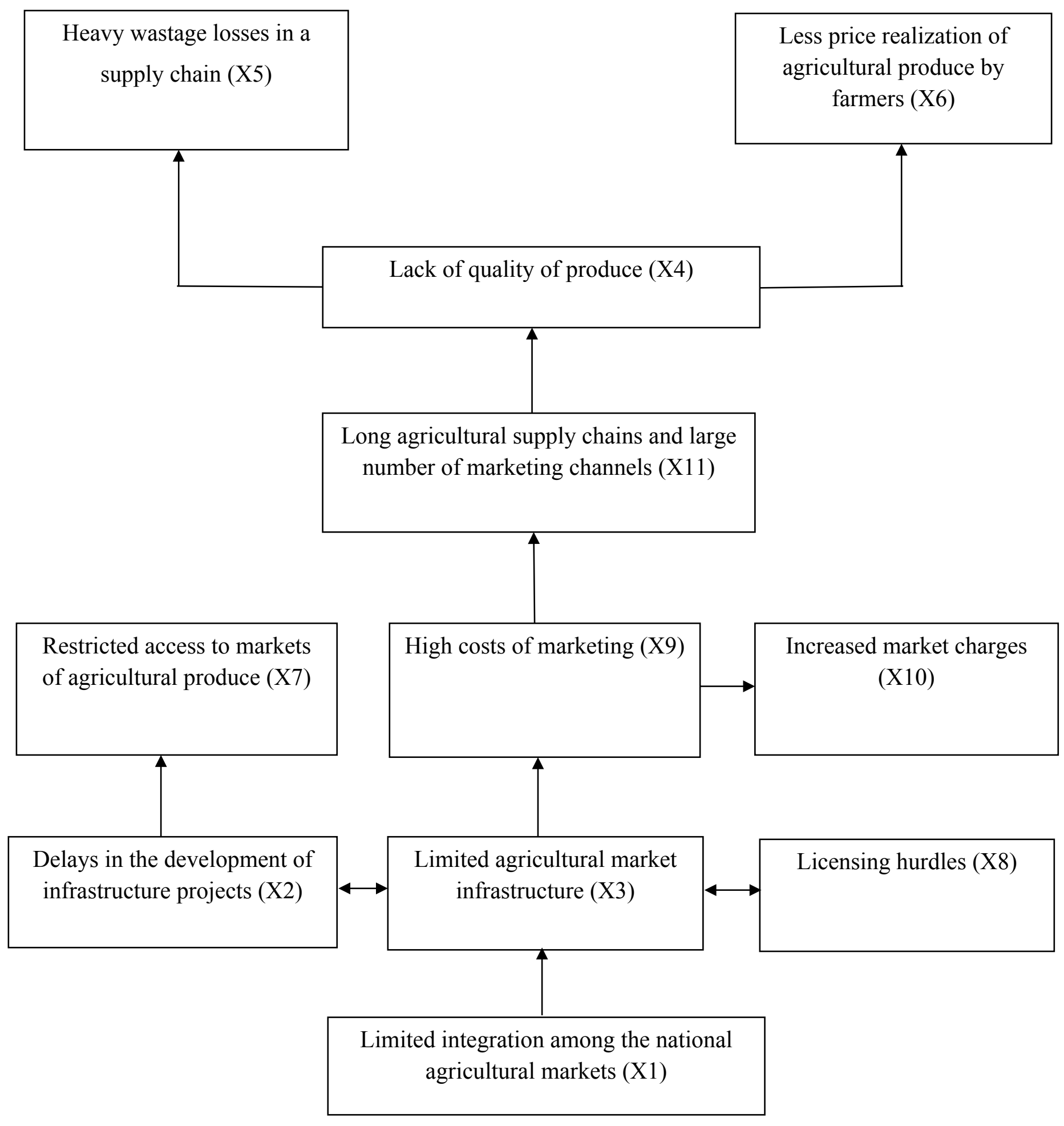

Figure 4 ISM based model of critical ASCM challenges. 


\subsection{MICMAC Analysis}

The MICMAC analysis helps to analyse and explain the factors/challenges considering their influential power and dependency. The influential (driving) power of a challenge is found by adding all 1's of the row, and dependency by adding all 1's of column (Raut et al., 2017). Figure 5 is known as a power matrix that has 4 clusters namely autonomous, dependent, linkage, and driving cluster. The autonomous segment consists of challenges having weak influential power and weak dependency, the dependent cluster covers the challenges with weak driving and high dependency, the linkage segment comprises of challenges having high driving power and high dependency. In the driving segment there are challenges having high driving power and low dependency.

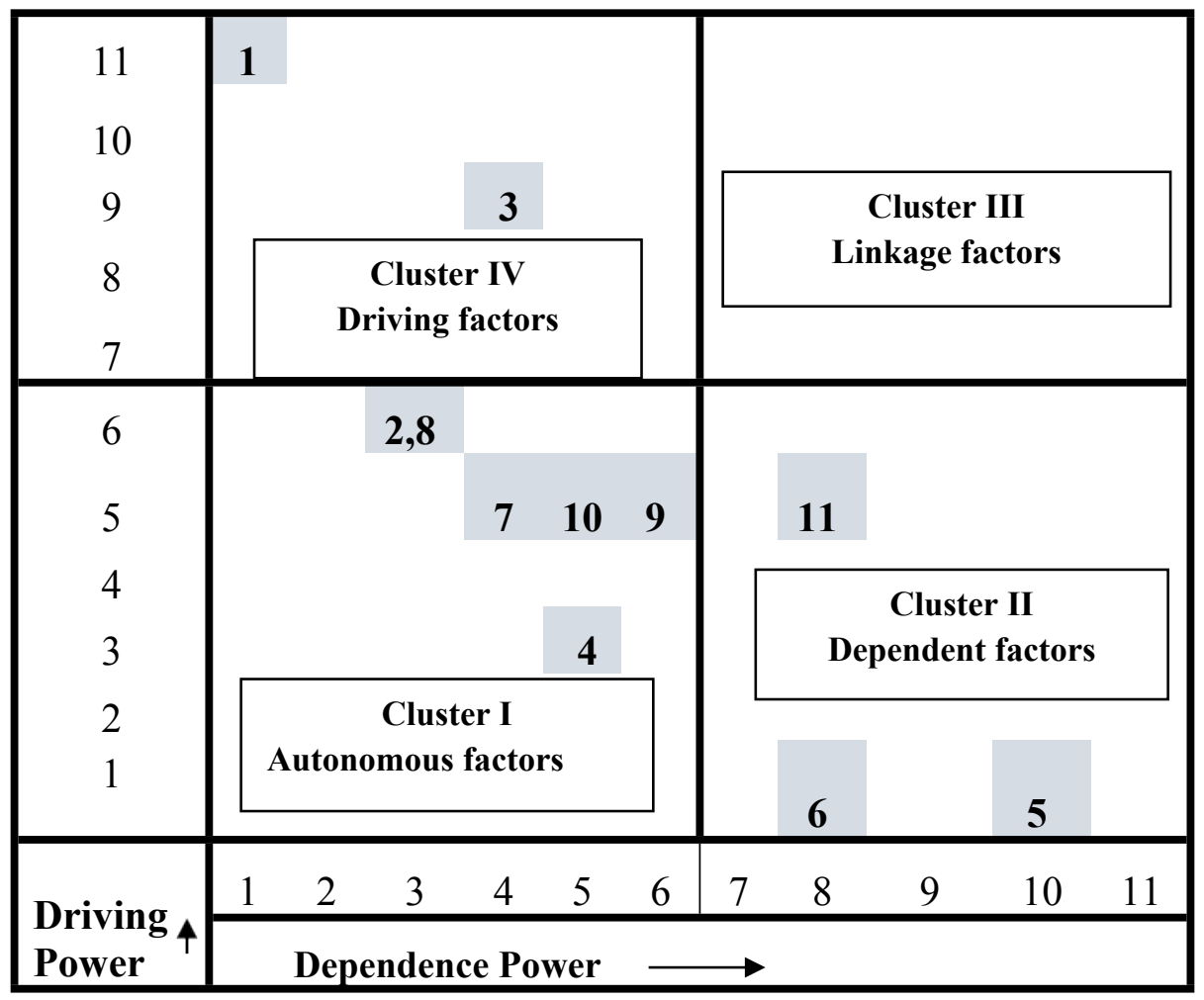

Figure 5 The driving and dependence power diagram (power matrix).

\section{Results and discussion}

\subsection{Results of casual relations among different criteria}

From the total influence matrix (Table 5), the values of $\mathrm{Ri}+\mathrm{Cj}$ and $\mathrm{Ri}-\mathrm{Cj}$ validate the degree of interrelationship between each challenge. The outcomes in Table 5 highlight the cause-effect 
value (R-C) of each challenge. A challenge with $\mathrm{R}-\mathrm{C}>0$ is considered as a causal factor/challenge, while a factor with $\mathrm{R}-\mathrm{C}<0$ is considered as an affect factor. It was found that "limited integration among the national agricultural markets (X1)", "high costs of marketing (X9)", "limited agricultural market infrastructure (X3)", "licensing hurdles (X8)", "delays in the development of infrastructure projects (X2)", and "increased market charges (X10)". It may be observed that "limited integration among the national agricultural markets(X1)" has the highest positive intensity showing that the role of integration among the national agricultural markets is more important for the ASCM. Also, "high costs of marketing(X9)" came out as one of the critical factors in ASCM challenges.

The effect factors identified are- "restricted access to markets of agricultural produces (X7)", "long agricultural supply chains and large number of marketing channels (X11)", "less price realization of agricultural produce by farmers (X6)", "lack of quality of produce (X4)", and "heavy wastage losses in a supply chain (X5)".These are influenced by cause factors which control the ASCM. Among the effect group, "lack of backwards-forward integration from farmer to consumer (X7)", is close to zero line. It indicates that it is not getting affected by the causal factors and a challenge namely "heavy wastage losses in a supply chain(X5)" is found to have the least weight of importance when it comes to ASCM challenges.

In formulating the interdependency matrix (Table 6), the highest prominence was preferred. The factor/challenge (X9) with the highest value of $(\mathrm{R}+\mathrm{C})$ is 4.091 . Based on the table, the development of overall influence matrix of ASCM challenges is prepared. The overall significant causal relationship diagram is indicated in Figure 2 and illustrates general pattern and relationship between all challenges simultaneously. From the figure, it is clear that "limited integration among the national agricultural markets(X1)" is found to be the most important causal factor. It implies that the limited integration among the national agricultural markets will considerably affect the remaining factors/challenges. Limited integration among the national agricultural market facilities is responsible for establishing the goals, which save significant losses in the ASCM. Based on the threshold value $(\lambda=0.148)$ prepared the reachability matrix of ASCM challenges.

The crucial factors identified through the Delphi technique are modelled using the DEMATELISM methodology in various hierarchical levels as shown in Figure 4. The top three barriers of the model (level I and level II) namely heavy wastage losses in a supply chain (X5), less price realisation of agricultural produce by farmers (X6), and lack of quality of produce (X4) are less 
significant than the other eight barriers driving these hindrances. At the middle stage (level III, and level IV) there are four barriers, namely long agricultural supply chains and a large number of marketing channels (X11), restricted access to markets of agricultural produce (X7), high costs of marketing (X9), and increased market charges (X10). These four are the barriers that are driving the factors above their level and are estimated to have moderate significance. At the bottom of the hierarchy, there are four factors, three at level V, namely delays in the development of infrastructure projects (X2), limited agricultural market infrastructure (X3), and licensing hurdles (X8). The most significant challenge of driving all other challenges above them is limited integration among the national agricultural markets (X1) which is at level VI.

The influential power and dependency diagram is indicated in Figure 5. The cluster I highlights the six autonomous barriers, namely delays in the development of infrastructure projects (X2) and licensing hurdles (X8), of which both obtain the driving power of 6 . Three barriers, namely restricted access to markets of agricultural produce (X7), increased market charges (X10), and high costs of marketing (X9), are found to have an influential power of 5. The least important factor of this cluster is a lack of quality of produce (X4) whose driving power intensity is 3 . In the cluster II, there are three dependent factors, namely long agricultural supply chains and large number of marketing channels (X11) which have a driving power of 5, and two hindrances, namely heavy wastage losses in a supply chain (X5), and less price realization of agricultural produce by farmers (X6) are found to be the least important in the developmental model as these barriers are having the least driving power of magnitude 1 . The linkage factors cluster has the most significant factors, which policymakers have to address for improving the effectiveness of the ASCM. These are limited integration among the national agricultural markets (X1), which secured the highest rank in the hierarchy having a driving power of 11 and limited agricultural market infrastructure (X3) that was found to have a driving power of 9.

\section{Conclusion}

Direct marketing of the commodities is one of the solutions to improve the efficiency of the ASCM. There should be a proper storage facility for the product; it helps farmers to holding the stock until the prices of the commodities become stabilised (Eskola, 2005; Sorathia et al., 2003). Directly after the harvest, the prices of the products are low, however if producers hold the produce for some time, they may yield higher profits. As the farmers do not have sufficient 
knowledge of the market prices, the trader buys the produce from the farmers at a meagre price and sells it to the consumers at high prices. Hence, there is a significant need of imparting this knowledge to the farmers. Additionally, there is a need for standardisation and complete rationalisation of the prices by legislative means. At present, there is a considerable gap between the strategies of marketing of agricultural commodities in India and abroad, and it needs to be addressed. The norms should be developed for reducing or eliminating the malpractices in the existing marketing system of agricultural production. Marketing bodies need to be trained alongside representatives from producers, merchants, local bodies, agents and government nominees to ensure a fair share for the farmers in the final price (Rao, 2008). In order to improve the ASCM, the government needs to improve the road facilities. Cheap and adequate transportation facilities should be made available so that farmers can take the product directly to the market instead of selling it to the local traders at low prices (Eskola, 2005; Sorathia et al., 2003). The government needs to provide sufficient storage facilities, which will help in reducing PHL and will yield benefits to farmers. The number of intermediaries involved in the process needs to be reduced to increase the financial gains of the farmers. There is a need to improve India's marketing system and it is recommended that the market committee needs to be reorganised so that market inspectors can continuously check the prices of agricultural produce. The above should be supported by strict laws and provisions should be made for building new markets near the production centres. In addition, information about supply and demand of produce should be shared via television, radio, newspapers. The grading of the agricultural produce should be carried out efficiently and the proposed infrastructure should take the quality of the produce and its safety into consideration. Furthermore, sufficient funds should be allocated to research to improve the efficiency of the marketing system.

\section{Limitations, future scope, and managerial implications of the study}

The obtained results of the methodology for the analysis apply to the ASCM sector only and cannot make generic to all other sectors as the rules of weights and concerned factors vary considerably from domain to domain. The study of identification and modelling the critical challenges in the ASCM sector using DEMATEL- ISM methodology provides important perspectives regarding the interrelationship between factors in forming guidelines for practitioners and researchers. 
In order to employ the ISM approach effectively, the user need to have sufficient information of the tool, and be adequately proficient in interpreting the identified data and to operate the computer facilities (Gardas et al., 2017b; Sushil, 2012). The interrelationship established between the identified challenges depends entirely on the judgments of the expert panel, which are not bias free. To overcome these limitations and for enhancing the accurateness of the developed model or to validate the same, combined methodology may be utilised (Mishra et al., 2018; Narkhede et al., 2017). Taking into consideration more factors/challenges in other investigations would provide better outcomes. In the future, structural equation modelling (SEM) methodology will be utilised for the validation of the developed DEMATEL- ISM model (Pawaskar et al., 2018).

\section{Managerial implications}

The reduction or elimination of the barriers to practical ASCM help in achieving balance among all three dimensions of sustainability, i.e., economic, social, and ecological. It has great strategic importance and is an MCDM problem. The present study proposes a framework for guiding the marketing policymakers and various members involved in the entire process of marketing and supply chain of the product, to better understand the problems regarding the challenges of ASCM. Furthermore, the significant barriers are recognized and modelled and valued insights drawn from the developed hierarchical model and MICMAC analysis. This analysis will help the policy and decision makers at different levels of the case supply chain to form effective strategies for improving the effectiveness of the ASCM. The time needed for implementing the strategies and tools effectively should be analysed. It is worth noting that implementation of effective marketing strategies will help farmers to obtain their fair share of the price of the produce. It improves competitiveness among the various members, decreases the cost of the produce, reduces ecological disasters, increases employability in the region, and reduces waste.

\section{References}

Abdelkader, M., \& Delali, A. (2012). Support system based on GIS and weighted sum method for drawing up of land suitability map for agriculture. Application to durum wheat cultivation in the area of Mleta (Algeria). Spanish Journal of Agricultural Research, 10(1), 34-43.

Altuntas, S., \& Dereli, T. (2015). A novel approach based on DEMATEL method and patent citation analysis for prioritizing a portfolio of investment projects. Expert systems with Applications, 42(3), 1003-1012. 
AMPR. 2013. Final report of committee of state ministers. Incharge of agricultural marketing to promote reforms. Ministry of Agriculture, Department of Agriculture and Cooperation, Government of India (http://agmarknet.nic.in/stminprreform.pdf, accessed on 12.10.2016).

Ashtianipour, Z., \& Zandhessami, H. (2015, August). An integrated ISM-DEMATEL model for evaluation of technological innovation capabilities' impact on the competitiveness of Small \& Medium Size Enterprises (SMEs). In Management of Engineering and Technology (PICMET), 2015 Portland International Conference on (pp. 322-334). IEEE.

Awasthi, A., \& Grzybowska, K. (2014). Barriers of the supply chain integration process. In Logistics Operations, Supply Chain Management and Sustainability (pp. 15-30). Springer, Cham.

Bag, S. (2017). Identification of Green Procurement Drivers and Their Interrelationship Using Total Interpretive Structural Modelling. Vision, 21(2), 129-142.

Bai, C., \& Sarkis, J. (2013). A grey-based DEMATEL model for evaluating business process management critical success factors. International Journal of Production Economics, 146(1), 281-292.

Balaji, M., \& Arshinder, K. (2016). Modeling the causes of food wastage in Indian perishable food supply chain. Resources, Conservation and Recycling, 114, 153-167.

Bartolini, F., Bazzani, G. M., Gallerani, V., Raggi, M., \& Viaggi, D. (2007). The impact of water and agriculture policy scenarios on irrigated farming systems in Italy: An analysis based on farm level multi-attribute linear programming models. Agricultural systems, 93(1-3), 90-114.

Beikkhakhian, Y., Javanmardi, M., Karbasian, M., \& Khayambashi, B. (2015). The application of ISM model in evaluating agile suppliers selection criteria and ranking suppliers using fuzzy TOPSIS-AHP methods. Expert systems with Applications, 42(15-16), 6224-6236.

Bianchini, A., Pellegrini, M., Rossi, J., \& Saccani, C. (2018). Theoretical model and preliminary design of an innovative wet scrubber for the separation of fine particulate matter produced by biomass combustion in small size boilers. Biomass and Bioenergy, 116, 60-71.

Büyüközkan, G., \& Güleryüz, S. (2016). An integrated DEMATEL-ANP approach for renewable energy resources selection in Turkey. International Journal of Production Economics, 182, 435-448.

Büyüközkan, G., \& Güleryüz, S. (2016). Multi criteria group decision making approach for smart phone selection using intuitionistic fuzzy TOPSIS. International Journal of Computational Intelligence Systems, 9(4), 709-725.

Commodity Online. 2007. How much Food does India Waste? (http://www.rediff.com/money/2007/mar/16food.htm, accessed on 11.22.2016).

De-Qun, Z., \& Ling, Z. (2008). Establishing hierarchy structure in complex systems based on the integration of DEMATEL and ISM. Journal of Management Sciences in China, 11(2), 20-26.

dos Muchangos, L. S., Tokai, A., \& Hanashima, A. (2015). Analyzing the structure of barriers to municipal solid waste management policy planning in Maputo city, Mozambique. Environmental development, 16, 76-89.

Eskola E. 2005. Agricultural marketing and supply chain management in Tanzania: A case study. Dar es Salaam: Economic and Social Research Foundation (http://www.tanzaniagateway.org/docs/agriculturalmarketingandsupplychainmanagem entintanzania.pdf, accessed on 12.11.2016). 
FAO. 2010. Reducing Post-Harvest Losses in Grain Supply Chains in Africa. Report of FAOWorld bank workshop held from 18- 19th March, 2010 in Rome, Italy.

Gardas, B. B., Raut, R. D., \& Narkhede, B. (2017a). Modeling causal factors of post-harvesting losses in vegetable and fruit supply chain: An Indian perspective. Renewable and Sustainable Energy Reviews, 80, 1355-1371.

Gardas, B. B., Raut, R. D., \& Narkhede, B. E. (2017b). A state-of the-art survey of interpretive structural modelling methodologies and applications. International Journal of Business Excellence, 11(4), 505-560.

Gardas, B. B., Raut, R. D., \& Narkhede, B. (2018a). Evaluating critical causal factors for postharvest losses (PHL) in the fruit and vegetables supply chain in India using the DEMATEL approach. Journal of Cleaner Production, 199, 47-61.

Gardas, B. B., Raut, R. D., \& Narkhede, B. (2018b). Modelling the challenges to sustainability in the textile and apparel (T\&A) sector: A Delphi-DEMATEL approach. Sustainable Production and Consumption, 15, 96-108.

Gardas, B. B., Raut, R. D., \& Narkhede, B. (2018c). Reducing the exploration and production of oil: Reverse logistics in the automobile service sector. Sustainable Production and Consumption, 16, 141-153.

Govindan, K., Azevedo, S. G., Carvalho, H., \& Cruz-Machado, V. (2015). Lean, green and resilient practices influence on supply chain performance: interpretive structural modeling approach. International Journal of Environmental Science and Technology, 12(1), 15-34.

Govindan, K., \& Chaudhuri, A. (2016). Interrelationships of risks faced by third party logistics service providers: A DEMATEL based approach. Transportation Research Part E: Logistics and Transportation Review, 90, 177-195.

Grzybowska, K. (2012). Sustainability in the supply chain: Analysing the enablers. In Environmental issues in supply chain management (pp. 25-40). Springer, Berlin, Heidelberg.

Hsu, C. W., Kuo, T. C., Chen, S. H., \& Hu, A. H. (2013). Using DEMATEL to develop a carbon management model of supplier selection in green supply chain management. Journal of cleaner production, 56, 164-172.

Jha, M. K., Raut, R. D., Gardas, B. B., \& Raut, V. (2018). A sustainable warehouse selection: an interpretive structural modelling approach. International Journal of Procurement Management, 11(2), 201-232.

Kader, A. A. (2004, June). Increasing food availability by reducing postharvest losses of fresh produce. In V International Postharvest Symposium 682 (pp. 2169-2176).

Kasso, M., Bekele, A. (2016). Post-harvest loss and quality deterioration of horticultural crops in Dire Dawa Region, Ethiopia. Journal of the Saudi Society of Agricultural Sciences (http://ac.els-cdn.com/S1658077X15300837/1-s2.0-S1658077X15300837-

main.pdf? tid=f6ec0936-c426-11e6-9e2e00000aab0f02\&acdnat $=1481958411 \quad 9 \mathrm{~b} 396145 \mathrm{c} 2 \mathrm{~d} 378 \mathrm{c} 6723570 \mathrm{a} 173331681$, accessed on 12.17.2016).

Kaur, J., Sidhu, R., Awasthi, A., Chauhan, S., \& Goyal, S. (2018). A DEMATEL based approach for investigating barriers in green supply chain management in Canadian manufacturing firms. International Journal of Production Research, 56(1-2), 312332.

Kiaya, V. (2014). Post-harvest losses and strategies to reduce them. Technical Paper on Postharvest Losses, Action Contre la Faim (ACF); 1-25. (http://s3.amazonaws.com/academia.edu.documents/45278162/POST HARVEST L OSSES.pdf?AWSAccessKeyId=AKIAJ56TQJRTWSMTNPEA\&Expires=14819673 
47\&Signature $=\mathrm{gz} \% 2 \mathrm{Ba} 90 \mathrm{qxprFhMXrrUgJtOBnofkQ} \% 3 \mathrm{D} \&$ response-contentdisposition $=$ inline $\% 3 \mathrm{~B} \% 20$ filename $\% 3$ DPOSTHARVEST LOSSES_AND_STRATEGIES TO RE.pdf, accessed on 12.17.2016).

Kumar, A., \& Dixit, G. (2018). An analysis of barriers affecting the implementation of e-waste management practices in India: A novel ISM-DEMATEL approach. Sustainable Production and Consumption, 14, 36-52.

Leveson, N. G. (2011). Applying systems thinking to analyze and learn from events. Safety Science, 49(1), 55-64.

Li, Y., \& Mathiyazhagan, K. (2018). Application of DEMATEL approach to identify the influential indicators towards sustainable supply chain adoption in the auto components manufacturing sector. Journal of Cleaner Production, 172, 2931-2941.

Lorentz, H., Yew Wong, C., \& Hilmola, O. P. (2007). Emerging distribution systems in Central and Eastern Europe: Implications from two case studies. International Journal of Physical Distribution \& Logistics Management, 37(8), 670-697.

Luthra, S., Garg, D., \& Haleem, A. (2015). An analysis of interactions among critical success factors to implement green supply chain management towards sustainability: An Indian perspective. Resources Policy, 46, 37-50.

Mishra A. K, Bhandari P. (2013). A study on agricultural marketing with special reference to Chhattisgarh state. International Journal of Research in Business Management, 1(7):13-20.

Mishra, S., Raut, R. D., Narkhede, B. E., Gardas, B. B., \& Priyadarshinee, P. (2018). To investigate the critical risk criteria of business continuity management by using analytical hierarchy process. International Journal of Management Concepts and Philosophy, 11(1), 94-115.

Najafabadi, M. O. (2011). Agricultural Marketing Challenges and Barriers in Iran. African Journal of Business Management, 5(35), 13580-13581.

Narkhede, B. E., Raut, R., Gardas, B., Luong, H. T., \& Jha, M. (2017). Selection and evaluation of third party logistics service provider (3PLSP) by using an interpretive ranking process (IRP). Benchmarking: An International Journal, 24(6), 1597-1648.

Narkhede, B. E., \& Gardas, B. B. (2018). Hindrances to sustainable workforce in the upstream oil and gas industries-interpretive structural modelling approach. International Journal of Business Excellence, 16(1), 61-81.

Negi, S., \& Anand, N. (2015). Supply Chain of Fruits \& Vegetables' Agribusiness in Uttarakhand (India): Major Issues and Challenges. Journal of Supply Chain Management Systems, 4(1), 43-57.

Ocampo, L. A., Tan, T. A. G., \& Sia, L. A. (2018). Using fuzzy DEMATEL in modeling the causal relationships of the antecedents of organizational citizenship behavior (OCB) in the hospitality industry: A case study in the Philippines. Journal of Hospitality and Tourism Management, 34, 11-29.

Parfitt, J., Barthel, M., \& Macnaughton, S. (2010). Food waste within food supply chains: quantification and potential for change to 2050. Philosophical Transactions of the Royal Society of London B: Biological Sciences, 365(1554), 3065-3081.

Pawaskar, U. S., Raut, R. D., \& Gardas, B. B. (2018). Assessment of Consumer Behavior Towards Environmental Responsibility: A Structural Equations Modeling Approach. Business Strategy and the Environment, 27(4), 560-571.

Pfohl, H. C., Gallus, P., \& Thomas, D. (2011). Interpretive structural modeling of supply chain risks. International Journal of physical distribution \& logistics management, 41(9), 839-859. 
Piech, B., \& Rehman, T. (1993). Application of multiple criteria decision making methods to farm planning: A case study. Agricultural Systems, 41(3), 305-319.

Prakash, T. N. (2003, December). Land suitability analysis for agricultural crops: a fuzzy multicriteria decision making approach. ITC.

Prusky, D. (2011). Reduction of the incidence of postharvest quality losses, and future prospects. Food Security, 3(4), 463-474.

Qiu, Z. (2005). Using multi-criteria decision models to assess the economic and environmental impacts of farming decisions in an agricultural watershed. Review of Agricultural Economics, 27(2), 229-244.

Rajendran, G., Karthikesan, M. P. (2014). Agricultural Marketing in India-An Overview. Asia Pacific Journal of Research, 1(17):159-164.

Rao MS. 2008. Where knowledge is wealth (http://profmsr.blogspot.in/2008/10/problems-andprospects-in-agricultural.html , accessed on 12.10.2016).

Raut, R. D., Narkhede, B., \& Gardas, B. B. (2017). To identify the critical success factors of sustainable supply chain management practices in the context of oil and gas industries: ISM approach. Renewable and Sustainable Energy Reviews, 68, 33-47.

Raut, R. D., Priyadarshinee, P., Gardas, B. B., \& Jha, M. K. (2018a). Analyzing the factors influencing cloud computing adoption using three stage hybrid SEM-ANN-ISM (SEANIS) approach. Technological Forecasting and Social Change.

Raut, R., Narkhede, B. E., Gardas, B. B., \& Luong, H. T. (2018b). An ISM approach for the barrier analysis in implementing sustainable practices: The Indian oil and gas sector. Benchmarking: An International Journal, 25(4), 1245-1271.

Ravi, V. (2015). Analysis of interactions among barriers of eco-efficiency in electronics packaging industry. Journal of Cleaner Production, 101, 16-25.

Ren, J., Tan, S., Goodsite, M. E., Sovacool, B. K., \& Dong, L. (2015). Sustainability, shale gas, and energy transition in China: assessing barriers and prioritizing strategic measures. Energy, 84, 551-562.

Roy M. (2012). Agricultural marketing: new challenges. International Journal of Humanities and Applied Sciences, 1(2): 54-57.

Safdari Ranjbar, M., Akbarpour Shirazi, M., \& Lashkar Blooki, M. (2014). Interaction among intra-organizational factors effective in successful strategy execution: An analytical view. Journal of Strategy and Management, 7(2), 127-154.

Sharma, G., \& Singh, S. P. (2011). Economic analysis of post-harvest losses in marketing of vegetables in Uttarakhand. Agricultural Economics Research Review, 24(2), 309-315.

Shukla, M., \& Jharkharia, S. (2013). Agri-fresh produce supply chain management: a state-ofthe-art literature review. International Journal of Operations \& Production Management, 33(2), 114-158.

Singh, S. P., Sikka, B.K., Singh, A. (2009). Supply Chain Management and Indian Fresh Produce Supply Chain: Opportunities and Challenges (http://citeseerx.ist.psu.edu/viewdoc/download?doi=10.1.1.499.707\&rep=rep1\&type $=$ pdf, accessed on 08.30.2016).

Song, W., \& Cao, J. (2017). A rough DEMATEL-based approach for evaluating interaction between requirements of product-service system. Computers \& Industrial Engineering, 110, 353-363.

Sorathia, V., Laliwala, Z., \& Chaudhary, S. (2005, July). Towards agricultural marketing reforms: Web services orchestration approach. In Services Computing, 2005 IEEE International Conference on (Vol. 1, pp. 260-267). IEEE. 
Sudharshan, G. M., \& Anand, M. B. (2013). Marketing and post-harvest losses in fruits: its implications on availability and economy-A study on pomegranate in Karnataka. Int. J. Manag. Soc. Sci. Res., 2, 34-43.

Sushil. (2012). Interpreting the interpretive structural model. Global Journal of Flexible Systems Management, 13(2): 87-106.

Tzeng, G. H., Chiang, C. H., \& Li, C. W. (2007). Evaluating intertwined effects in e-learning programs: A novel hybrid MCDM model based on factor analysis and DEMATEL. Expert systems with Applications, 32(4), 1028-1044.

Venkatesh, V. G., Zhang, A., Luthra, S., Dubey, R., Subramanian, N., \& Mangla, S. (2017). Barriers to coastal shipping development: An Indian perspective. Transportation Research Part D: Transport and Environment, 52, 362-378.

Vyas VK. 2014. Overview of agricultural marketing. Shodhganga; 70-99 (http://shodhganga.inflibnet.ac.in/bitstream/10603/25033/18/8.2.overview\%20of\%20 agricultural\%20marketing.pdf, accessed on 12.11.2016).

Wang, L., Cao, Q., \& Zhou, L. (2018). Research on the influencing factors in coal mine production safety based on the combination of DEMATEL and ISM. Safety Science, 103, 51-61. 